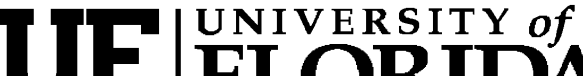 FLORIDA \\ IFAS Extension
}

\section{Visual Teaching Tools: Concept Maps ${ }^{1}$}

\author{
Lauren Dillard, Brian E. Myers ${ }^{2}$ \\ Introduction
}

Concept maps are one way to make classroom content easier for students to understand. These educational tools are a great way to simplify information by allowing students to visualize complex processes. They also engage student's creativity and higher order thinking skills.

\section{What Are Concept Maps}

Concept maps allow students and teachers to simplify complex information by showing relationships using lines and boxes. Regardless of the type of information being presented, all concept maps have a central idea. Depending on the relationship type, a concept map can illustrate a sequence of events, a cycle, or steps in a process. They are visually appealing and convey information quickly.

\section{Types of Concept Maps}

The format of the concept map will be influenced by the type of information in the presentation.

Concepts that require classification need a map that shows categorization. Maps for processes or sequencing have to allow for stages and sub-stages. Cause and effect relationships require a map that demonstrates multi-flow organization.

\section{Tree Maps}

A tree map classifies ideas into categories or groups. This type of map organizes information into levels according to importance, size or attributes. In order to create a tree map the main category needs to be identified, followed by the sub-category and any further necessary information. This type of map illustrates the hierarchical classification of subjects; it represents which information is most important. This type of map can be useful for taxonomy, breed origins, or even to compare and contrast. Useful questions for constructing tree maps include: what is the main idea?; what are the sub-categories or sub-groups?; and is there any information that can be put into two groups?

\section{Flow Maps}

Flow maps graphically depict a sequence of events in order. They can be used to represent complex processes, and can help students identify various stages and sub-stages of an event. Among the subjects that can best be illustrated through a flow map are how-to demonstrations, environmental cycles, and steps for a laboratory analysis. Questions to consider when constructing a flow map include: what is the main idea or event?; what are the sub-stages of the event?; and are there any other relationships between the stages and sub-stages?

1. This document is AEC 390, one of a series of the Agricultural Education and Communication Department, Florida Cooperative Extension Service, Institute of Food and Agricultural Sciences, University of Florida. Original publication date May 2008. Visit the EDIS Web Site at http://edis.ifas.ufl.edu.

2. Lauren Dillard, graduate research assistant; Brian E. Myers, assistant professor; Department of Agricultural Education and Communication, Florida Cooperative Extension Service, Institute of Food and Agricultural Sciences, University of Florida, Gainesville, FL.

The Institute of Food and Agricultural Sciences (IFAS) is an Equal Opportunity Institution authorized to provide research, educational information and other services only to individuals and institutions that function with non-discrimination with respect to race, creed, color, religion, age, disability, sex, sexual orientation, marital status, national origin, political opinions or affiliations. U.S. Department of Agriculture, Cooperative Extension Service, University of Florida, IFAS, Florida A. \& M. University Cooperative Extension Program, and Boards of County Commissioners Cooperating. Larry Arrington, Dean 


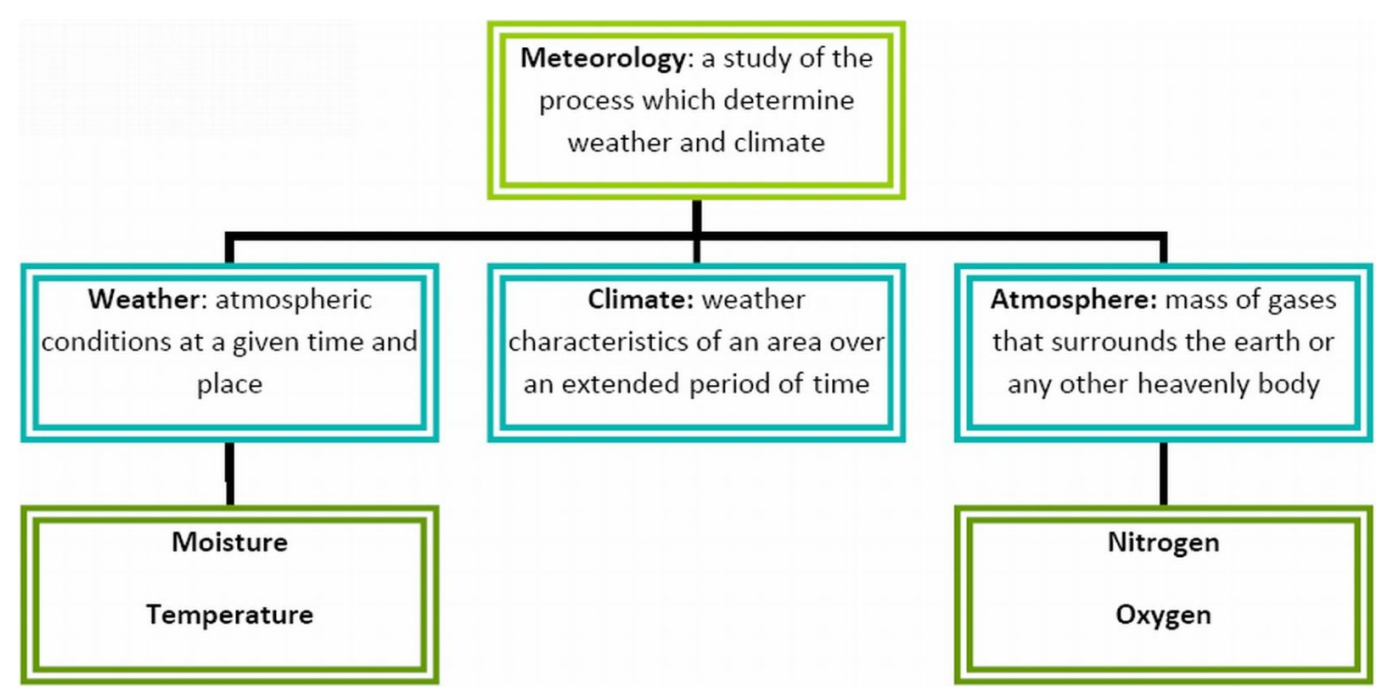

Figure 1. A tree map on the definitions of climate and weather.
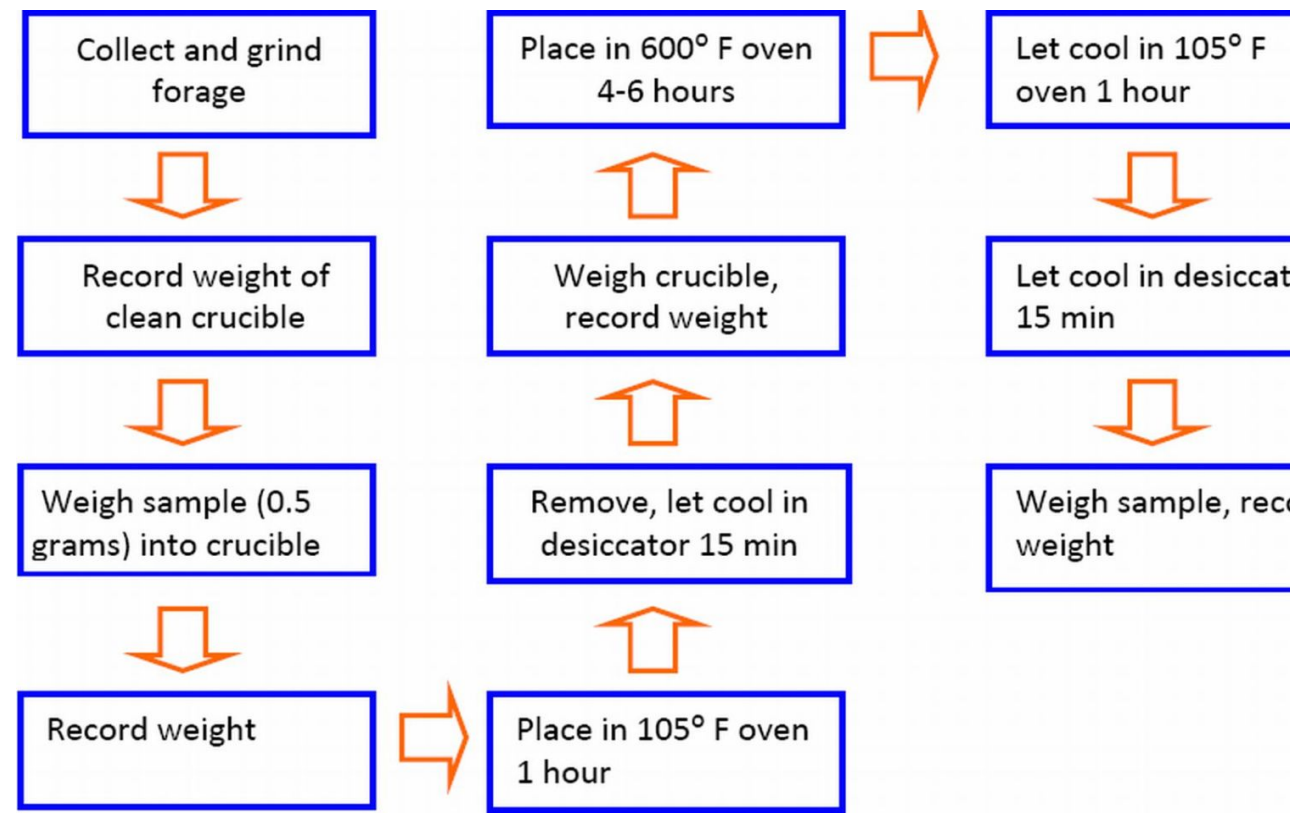

Let cool in desiccator $15 \mathrm{~min}$

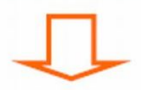

Weigh sample, record weight

Figure 2. A flow map about how to determine the dry matter weight of forage. 


\section{Multiflow Maps}

Often students easily understand simple one-to-one cause/effect relationships but tend to get lost when multiple outcomes result from multiple influences. Multi-flow maps help simplify complex cause/effect relationships by representing one central event with causes and effects depicted on either side. Multi-flow maps can be used for subjects like animal nervousness, weight gain or the weather. Questions to consider in constructing a multiflow map include: what are the causes and effects of this event?; which causes relate to which effects?; and which causes and effects are most important?

\section{Compare and Contrast}

A compare and contrast map can be used to summarize information about differences and similarities, and to analyze the positive and negative aspects of two issues, or topics. Questions to consider in constructing compare/contrast maps include: 1) what things are being compared?; 2) what attributes of each?; and 3) how can the similarities and differences be evaluated?

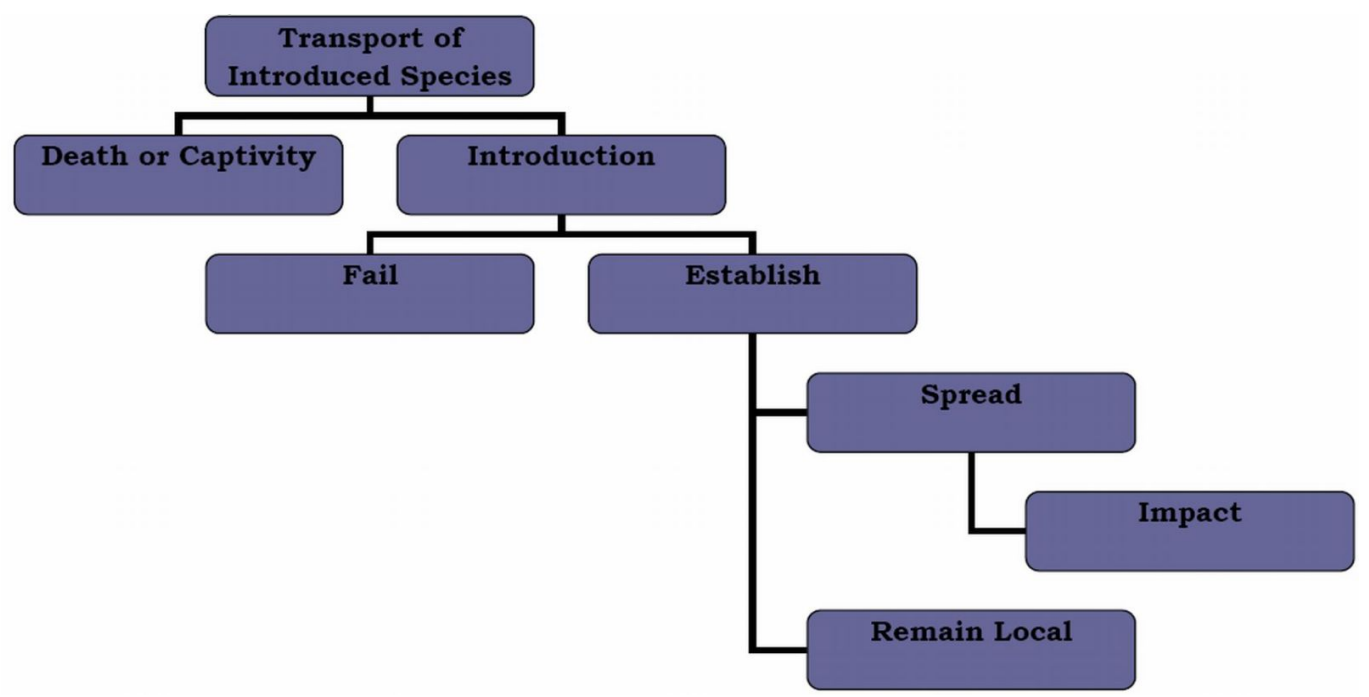

Figure 3. A multiflow map depicting the process of establishment for invasive species.

Table 1. A table comparing and contrasting corn and potatoes.

\begin{tabular}{||c|c|c||}
\hline \hline & Corn & Potato \\
\hline Origin & Mesopotamia & South America \\
\hline Growing Season & Summer & Summer \\
\hline Common Uses & Food Production and Biofuel & Food Production \\
\hline Growth Type & Above Ground & Tuberous \\
\hline
\end{tabular}




\section{Purpose of Concept Mapping}

Information is traditionally presented in printed text, with only words to describe the relationship between two or more things. This type of presentation can be monotonous and daunting to some learners. Concept maps help students visualize connections that may not appear when reading. Aside from simplifying printed information, they make learning more interesting, and enjoyable.

There are several benefits to concept maps. When they are developed properly, they can address multiple learning styles. They allow teachers to present information in a novel format that facilitates knowledge and thinking, and function as a learning tool for student centered activities. Another benefit is the positive influence concept maps have on retention of new knowledge; this benefit may accommodate the visual learner most of all, but most people appreciate the clarity of seeing relationships between two ideas.

\section{Summary}

Concept maps are great tools for any classroom regardless of grade level. By utilizing concept maps both students and teachers benefit from their ease of preparation and comprehension. Using visual tools to engage students is an effective technique that requires little effort. This type of teaching tool can be used for various learning or teaching styles, and is a great way to improve the presentation of any subject matter. 